\title{
Hyperacusis in Children with Attention Deficit Hyperactivity Disorder: A Preliminary Study
}

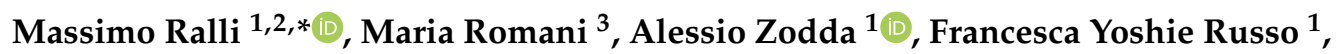 \\ Giancarlo Altissimi ${ }^{1}$, Maria Patrizia Orlando ${ }^{1}$, Maria Gloria Cammeresi ${ }^{1}$, Roberta Penge ${ }^{3,+}$ \\ and Rosaria Turchetta ${ }^{1,+}$ \\ 1 Department of Sense Organs, Sapienza University of Rome, Viale del Policlinico 155, 00100 Rome, Italy; \\ alessio.zodda@libero.it (A.Z.); francescayoshie.russo@uniroma1.it (F.Y.R.); \\ giancarlo.altissimi@uniroma1.it (G.A.); mariapatrizia.orlando@uniroma1.it (M.P.O.); \\ mariagloria.cammeresi@uniroma1.it (M.G.C.); rosaria.turchetta@uniroma1.it (R.T.) \\ 2 Center for Hearing and Deafness, University at Buffalo, Buffalo, NY 14214, USA \\ 3 Department of Pediatrics and Child Neuropsychiatry, Sapienza University of Rome, Viale del Policlinico 155, \\ 00100 Rome, Italy; maria.romani@uniroma1.it (M.R.); roberta.penge@uniroma1.it (R.P.) \\ * Correspondence: massimo.ralli@uniroma1.it; Tel.: +39-0649976808 \\ + These authors contributed equally to this work.
}

Received: 27 March 2020; Accepted: 21 April 2020; Published: 27 April 2020

\begin{abstract}
The association between hyperacusis and developmental disorders such as autism spectrum disorders has been extensively reported in the literature; however, the specific prevalence of hyperacusis in attention deficit hyperactivity disorder (ADHD) has never been investigated. In this preliminary study, we evaluated the presence of hyperacusis in a small sample of children affected by ADHD compared to a control group of healthy children. Thirty normal hearing children with a diagnosis of ADHD and 30 children matched for sex and age were enrolled in the study. All children underwent audiological and multidisciplinary neuropsychiatric evaluation. Hearing was assessed using pure tone audiometry and immittance test; ADHD was diagnosed following the Diagnostic and Statistical Manual of Mental Disorder criteria. Hyperacusis was assessed through the administration of a questionnaire to parents and an interview with children. Hyperacusis was diagnosed in 11 children $(36.7 \%)$ in the study group and in four children $(13.3 \%)$ in the control group; this difference was statistically significant $(p=0.03$ ). The preliminary results of this study suggest a higher presence of hyperacusis in children with attention deficit hyperactivity disorder compared to control children. More studies on larger samples are necessary to confirm these results.
\end{abstract}

Keywords: hyperacusis; attention deficit hyperactivity disorder; autism spectrum disorders; hearing

\section{Introduction}

Hypersensitivity to sound (hyperacusis) is described as a reduced tolerance to sounds of average intensity, sometimes accompanied by painful sensitivity to ordinary environmental sounds, with perceptual, psychological and social dimensions [1]. The causes of hyperacusis are still debated; recent imaging studies indicate the hyperexcitability of specific brain areas as a common finding in these patients [2-8]. Available evidence suggests that hyperacusis could originate from functional alterations in the central nervous system correlated to generalized hyperactivity following an increase in the gain of auditory and extra-auditory pathways and to greater anxiety or emotional response to sound $[5,7,9,10]$. There is a growing awareness that, although more prevalent during adulthood, children may also experience hyperacusis [11-15]. Data on the prevalence and characteristics of this condition during childhood are fragmented; the estimated prevalence varies between 3.2\% and 17.1\% 
of the pediatric population $[13,16]$. Hyperacusis can have significant effects on children's behavior; sounds can be perceived as painful and trigger avoidance conducts, leading to isolation and influencing social interactions and daily activities with potential consequences on education, communication and learning $[17,18]$.

Attention deficit hyperactivity disorder (ADHD) is a childhood-onset neurodevelopmental condition characterized by marked, persistent and maladaptive age-inappropriate levels of inattention, hyperactivity, and impulsivity $[19,20]$. The estimated incidence of ADHD is $7 \%$ of the pediatric population and $4 \%$ of the adult population; the rates of the disorder in the general population have been increasing over the past decade also thanks to more accurate diagnostic protocols [21-23]. ADHD is mainly diagnosed during primary school; symptoms include common traits with autism spectrum disorders (ASD)—although ADHD is not part of the autism spectrum—and include accentuated restlessness and evident presence of cognitive symptoms, such as inattention, easy distractibility, impulsiveness, scholastic difficulties, avoidance of cognitive tasks, impulsive reactions, low self-esteem and sometimes low olfactory threshold [24-27]. ADHD is the most common comorbid psychiatric condition in patients with ASD, with comorbidity rates as high as 70\% [28]. Similarly, ASD traits can be found in children with ADHD, with nearly $12 \%$ having a diagnosis of ASD [29]. The causes underlying this relationship are still unclear, although specific genetic variants have been suspected [30].

The association between hyperacusis and developmental disorders such as ASD has been extensively reported in the literature; a higher prevalence of hyperacusis has been reported in ASD and Williams syndrome [17,31-36]. However, the prevalence of hyperacusis in children with ADHD has never been specifically investigated. The aim of this preliminary study is to evaluate the prevalence of hyperacusis in a cohort of normal hearing pediatric patients affected by ADHD compared to a control group of healthy children matched for age and sex.

\section{Materials and Methods}

\subsection{Study Sample}

The study participants consisted of 60 children of both sexes, aged between 4 and 12 years, with clinically normal hearing. Children were divided into two groups: a study group of children with neuropsychiatric diagnosis of ADHD combined type $(n=30)$, and a control group of healthy children matched for age and sex $(n=30)$.

Clinically normal hearing was defined according to the American Academy of Otolaryngology and American Council of Otolaryngology [37] as an individual hearing threshold $\geq 25 \mathrm{~dB} H \mathrm{HL}$ at frequencies from 250 to $4000 \mathrm{~Hz}$ at the octave scale in both ears.

ADHD was diagnosed following the fifth edition of the Diagnostic and Statistical Manual of Mental Disorder (DSM-5) criteria, and only children with a diagnosis of ADHD, combined presentation, were included [38].

Exclusion criteria were the presence of hearing loss, recent episodes of otitis media with effusion, previous ear surgery, ADHD with predominantly inattentive or predominantly hyperactive/impulsive presentation, a Full-Scale Intelligence Quotient $<85$, and concomitant neuropsychiatric comorbidities.

The study was approved by the local Ethic Committee of our University Department (14/2019, 23.07.2019) and was performed in accordance with the Helsinki declaration and its amendments. Informed consent was obtained from the parents of the participants.

\subsection{Diagnosis of Attention Deficit Hyperactivity Disorder}

Diagnosis of ADHD was performed in the Department of Human Neuroscience of our university. Children were referred on the recommendation of parents, teachers or pediatricians. All children and parents underwent an initial interview with a child neuropsychiatrist who collected the child's history, followed by an evaluation performed by a multidisciplinary team of experts comprising a neuropsychiatrist and two psychologists. The diagnosis of ADHD was made following the DSM-5 
criteria for ADHD, combined presentation. Treatment was individually designed and adapted to the child's age and condition and may have included psychostimulants and behavior therapy, counseling, social skills training, psychotherapy and child and family education services.

\subsection{Auditory Evaluation}

Auditory evaluation was performed in the Department of Sense Organs, Pediatric Audiology Unit of our university. All patients underwent full otolaryngology examination, pure tone audiometry (PTA), and acoustic immittance test. PTA (Piano Clinical Audiometer Inventis, Padua, Italy) was measured at frequencies of 125, 250, 500, 1000, 2000, 3000, 4000, and $8000 \mathrm{~Hz}$. Acoustic immittance measures were performed to measure the functional integrity of the eardrum and middle ear anatomy using tympanometry tests and acoustic stapedial reflex tests (AT 235 Tympanometer, Interacoustics, Middelfart, Denmark).

\subsection{Diagnosis of Hyperacusis}

Hyperacusis in children was evaluated through the administration of a questionnaire to parents (PQ) (Table 1) and an interview with children (CI) (Table 2). Both questionnaire and interview were modified from Coelho et al. (2007) and translated into Italian, as already done in a previously published study from our group [11].

Table 1. Parent's questionnaire.

\begin{tabular}{cc}
\hline & Answer the Following Questions \\
\hline 1. & Do you think that your child is too sensitive to every day's sounds? \\
2. & Is there any sound that your child dislikes? \\
3. & Is there any sound that your child considers painful? \\
4. & Is there any sound that scares your child? \\
\hline 5. & Indicate Your Child's Most Frequent Reaction to Loud Sounds \\
6. & Cover ears \\
7. & Cries \\
8. & Escapes from sound \\
9. & Steps back to avoid sound \\
10. & Other \\
\hline
\end{tabular}

Table 2. Children's interview.

\begin{tabular}{ccccc}
\hline \multicolumn{5}{c}{ Answer the Following Questions } \\
\hline 1. & \multicolumn{4}{c}{ Can you hear well? } \\
2. & \multicolumn{4}{c}{$\begin{array}{c}\text { Do you hear a noise inside your ears or head? } \\
\text { Are you bothered by any kind of sound or noise? }\end{array}$} \\
\hline S. & \multicolumn{4}{c}{ Do any of the Following Sounds Annoy you? } \\
School recess & TV & Car & Toys & Firecrackers \\
Screams & Radio & Motorcycle & Balloons & Bombs \\
School bell & Mixer & Truck & Whistle & Thunder \\
\hline
\end{tabular}

The PQ was divided into two sections: the first examined hypersensitivity to everyday sounds reported by parents using four short and concise multiple-choice questions investigating the relationship that their children has with sounds. Each question had three possible answers: YES (4 points), DON'T KNOW (2 points) and NO (0 points) (Q1-4). The second section included six questions investigating the most common reactions of their children to sounds (Q5-10). A child was considered hypersensitive to sound if he obtained a score $>8$ points for questions $1-4$. 
The CI included three main questions investigating hearing loss, the presence of tinnitus and subjective hypersensitivity to sounds. Furthermore, it was asked of the children to indicate which sounds annoyed them from a list of 20 sounds. If a positive answer was given to the question "Are you bothered by any kind of sound or noise?" and the child indicated five or more sounds from the list of 20 sounds as annoying, the child was classified as "hypersensitive to sound."

Children were considered hyperacusic if they scored hypersensitive to sounds in both the PQ and the CI. The flowchart (Figure 1) outlines the criteria used to classify questionnaire and interview data and to define hyperacusis.

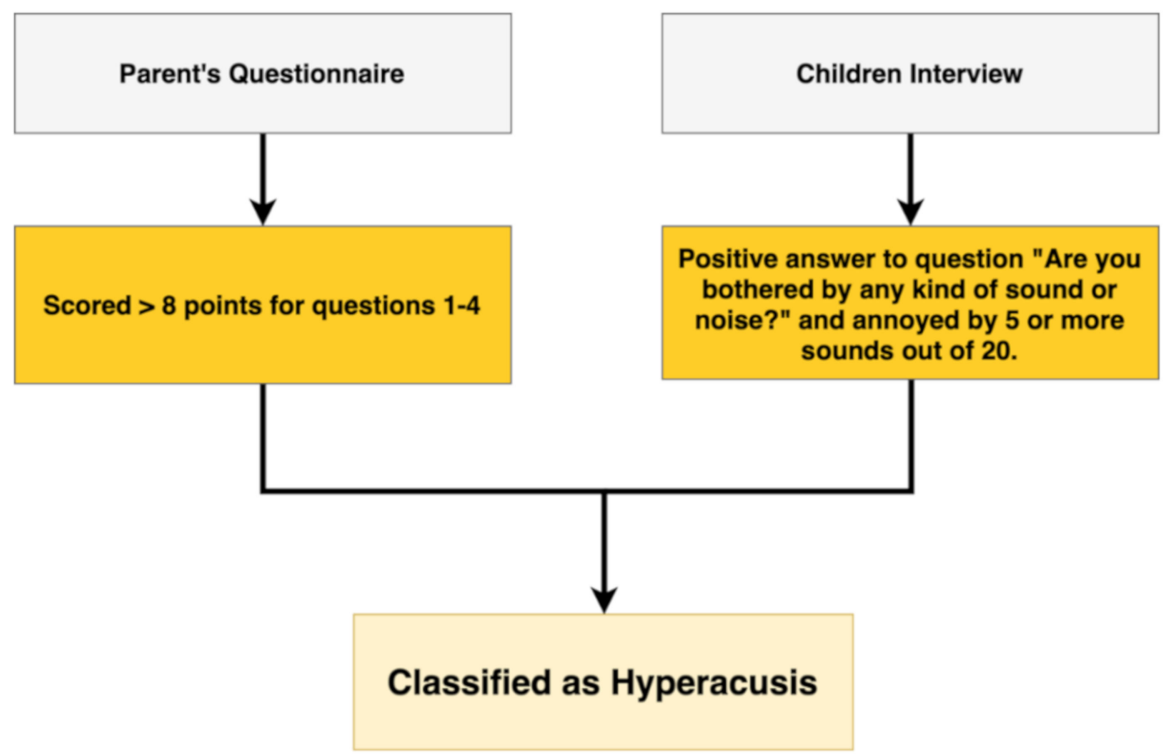

Figure 1. Flowchart showing the criteria used to classify questionnaire and interview data and to define hyperacusis. Children were considered hyperacusic if they scored hypersensitive to sound at both the parent's questionnaire and children's interview.

\subsection{Statistical Analysis}

Descriptive analysis was used to define the main clinical and demographic characteristics of the patients. Data were expressed as means \pm standard deviations. The statistical analysis was conducted using the Unpaired $t$ test to highlight differences in basic characteristics (age, sex) between groups (not expected) and any difference in prevalence of hyperacusis and answers to questionnaires. A $p$-value less than 0.05 was considered the cutoff for statistical significance. Prism Software version 8.3.1 (GraphPad Software LLC, San Diego, CA, USA) was used to perform statistical analysis.

\section{Results}

\subsection{Patients' Characteristics}

Thirty children with a clinical diagnosis of ADHD (study group) and 30 children matched for sex and age (control group) were enrolled in the study. In the study group, 25 children were males $(83.3 \%)$ and five were females (16.7\%). Mean age was 7.7 years (range: $5-12$ years; SD: 1.78, SE: 0.32). In the control group, 24 were males (80\%) and six were females (20\%). Mean age was 7.4 years (range: 4-12 years; SD: 1.883, SE: 0.3439). No significant differences were seen for age between the study and control group $(t=0.63, p=0.52)$.

All children in the study and control groups had normal hearing, with an average PTA $<25 \mathrm{~dB} H \mathrm{HL}$ for each frequency in the $250-4000 \mathrm{~Hz}$ range (Figure 2). 


\section{Pure Tone Audiometry}

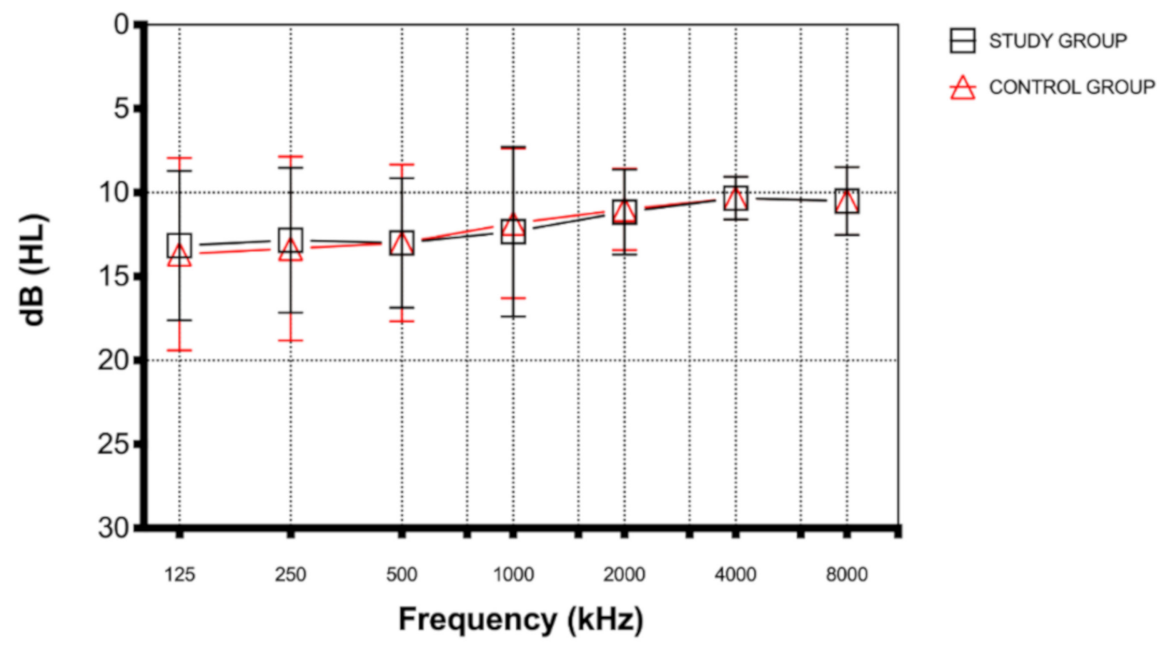

Figure 2. Pure tone audiometry (PTA) in the study and control groups. All children had normal hearing, with an average PTA $<25 \mathrm{~dB}$ HL for each frequency in the $250-4000 \mathrm{~Hz}$ range.

No significant differences were found for PTA between the two groups $(t=0.06, p=0.94)$. In the study group, 25 children $(83.3 \%)$ had a type-A tympanogram, three $(10 \%)$ a unilateral type-C tympanogram and two $(6.7 \%)$ a bilateral type-C tympanogram. In the control group, 23 children $(76.7 \%)$ had a type-A tympanogram, three $(10 \%)$ a unilateral type-C tympanogram and four $(13.3 \%)$ a bilateral type-C tympanogram.

\subsection{Parent's Questionnaire}

Mean score for PQ in the study group was 6.4 compared to 3.4 in the control group. Difference for mean PQ score between the study and control groups was statistically significant $(t=2.63, p=0.01$, $d=0.67$ ) (Figure 3).

\section{Parent's questionnaire}

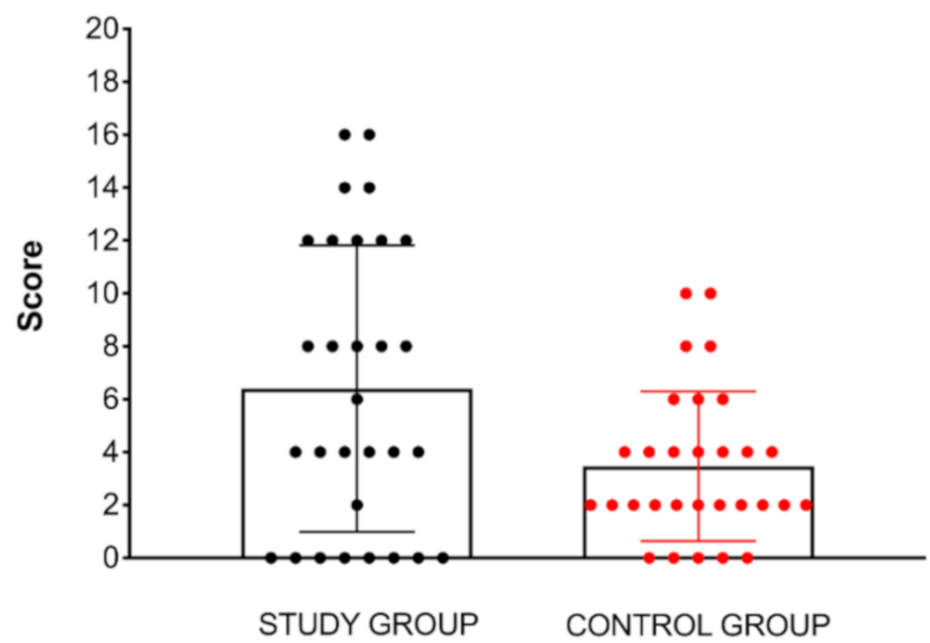

Figure 3. Results of the parent's questionnaire for hyperacusis. Mean score in the study group was 6.4 compared to 3.4 in the control group. Difference for mean score between the study and control groups was statistically significant $(p=0.01)$. 
In the study group, PQ was positive for hypersensitivity to sound (score $>8$ ) in 14 children (46.7\%; range $8-16$; mean $=11.4)$ and negative in 16 children $(53.3 \%$; range $0-6$; mean $=2)$. In the control group, PQ was positive in four children (13.3\%; range 8-16; mean $=9$ ) and negative in 26 children $(86.7 \%$ range $0-6$; mean $=2.7)$.

Specific results of questions 5-10 for both groups are detailed in Figure 4.

\section{Parent's questionnaire}

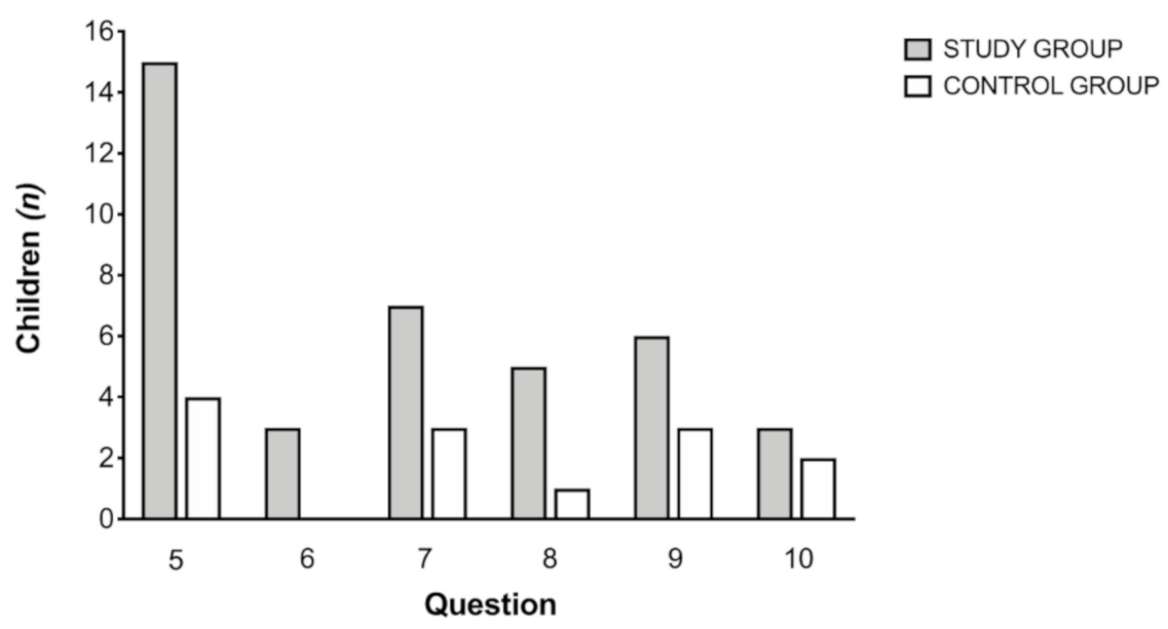

Figure 4. Specific results of questions 5-10 of the parent's questionnaire for children in the study and control groups. In the study group, a positive response was most found for question 5-cover ears, followed by question 7-escape from sounds, and question 9-saying "it hurts". In the control group, a positive response was mostly found for question 5 , followed by question 7 and question 9 .

In the study group, a positive response was mostly found for question 5-cover ears (50\%), followed by question 7-escape from sounds (23.3\%), and question 9-saying "it hurts" (20\%). In the control group, a positive response was found for question 5-cover ears (13.3), followed by question 7 -escape from sounds (10\%), and question 9-saying "it hurts" (10\%). Difference was statistically significant only for question $5(t=3.26, p=0.001)$, while it did not reach significance for question 6 $(t=1.79, p=0.07), 7(t=1.38, p=0.17), 8(t=1.73, p=0.08), 9(t=1.07, p=0.28)$, and $10(t=0.46$, $p=0.64)$.

\subsection{Children's Interview}

All children in both groups stated that they had normal hearing. Four children in the study group $(13.3 \%)$ and two in the control group (6.7\%) reported experiencing tinnitus $(t=0.85, p=0.39)$, while 25 children $(83.3 \%)$ in the study group and seven $(23.3 \%)$ in the control group reported being bothered by any kind of sound or noise $(t=5.73, p<0.0001, d=1.47)$.

A detailed analysis of the sounds that were reported by children to be annoying (total = 20 sounds) is shown in Table 3.

In the study group, 14 children were annoyed by $0-4$ sounds (46.7\%), $11(36.7 \%)$ by $5-9$ sounds and five $(16.7 \%)$ by more than 10 sounds. The most annoying sounds were classroom sounds and screams, followed by bombs and school bells. In the control group, 23 children were annoyed by $0-4$ sounds $(7.7 \%)$, six $(20 \%)$ by $5-9$ sounds and one $(3.3 \%)$ by more than 10 sounds. The most annoying sounds were screams and thunder, followed by bombs, classroom noise, school bells and firecrackers.

On average, children in the study group were annoyed by 5.4 sounds compared to three in the control group; the difference was statistically significant $(t=2.80, p=0.006, d=0.12)$. 
Table 3. Answers from children in the study and control group.

\begin{tabular}{ccc}
\hline \multirow{2}{*}{ Are You Annoyed by “... } & \multicolumn{2}{c}{ Number of Children that Considered the Sound Annoying } \\
\cline { 2 - 3 } & Study Group $(\boldsymbol{n}=\mathbf{3 0})$ & Control Group $(\boldsymbol{n}=\mathbf{3 0})$ \\
\hline School recess & $10(33.3 \%)$ & $4(13.3 \%)$ \\
Classroom noise & $16(53.3 \%)$ & $6(20 \%)$ \\
Screams & $16(53.3 \%)$ & $8(26.7 \%)$ \\
School bell & $11(36.7 \%)$ & $6(20 \%)$ \\
TV & $3(10 \%)$ & $3(10 \%)$ \\
Radio & $3(10 \%)$ & $1(3.3 \%)$ \\
Mixer & $8(26.7 \%)$ & $4(13.3 \%)$ \\
Telephone & $2(6.7 \%)$ & $1(3.3 \%)$ \\
Car & $5(16.7 \%)$ & $3(10 \%)$ \\
Motorcycle & $6(20 \%)$ & $4(13.3 \%)$ \\
Truck & $5(16-7 \%)$ & $3(10 \%)$ \\
Ambulance & $4(13.3 \%)$ & $2(6.7 \%)$ \\
Toys & $6(20 \%)$ & $3(10 \%)$ \\
Balloons & $10(33.3 \%)$ & $5(16.7 \%)$ \\
Whistle & $8(26.7 \%)$ & $4(13.3 \%)$ \\
Musical instruments & $8(26.7 \%)$ & $4(13.3 \%)$ \\
Bombs & $13(43.3 \%)$ & $7(23.3 \%)$ \\
Firecrackers & $9(30 \%)$ & $6(20 \%)$ \\
Thunders & $10(33.3 \%)$ & $8(26.7 \%)$ \\
Dogs & $8(26.7 \%)$ & $4(13.3 \%)$ \\
\hline
\end{tabular}

\subsection{Prevalence of Hyperacusis}

Hyperacusis was assessed based on PQ and CI results. In the study group, 11 children (36.7\%) scored positive in both the PQ and the CI and were classified as hyperacusic, while in the control group only four children (13.3\%) scored positive in both the PQ and the CI (Table 4).

Table 4. Identification of children with hyperacusis based on parent's questionnaire and children's interview.

\begin{tabular}{|c|c|c|c|c|c|c|c|}
\hline \multirow[t]{2}{*}{ ID \# } & \multicolumn{2}{|c|}{ Study Group } & \multirow[b]{2}{*}{$\begin{array}{l}\text { Bothered by } \\
\text { Sounds (Y/N) }\end{array}$} & \multirow[t]{2}{*}{ ID\# } & \multicolumn{2}{|c|}{ Control Group } & \multirow[b]{2}{*}{$\begin{array}{l}\text { Bothered by } \\
\text { Sounds (Y/N) }\end{array}$} \\
\hline & $\begin{array}{c}\text { Parent's } \\
\text { Questionnaire }\end{array}$ & $\begin{array}{l}\text { Children's } \\
\text { Interview }\end{array}$ & & & $\begin{array}{c}\text { Parent's } \\
\text { Questionnaire }\end{array}$ & $\begin{array}{l}\text { Children's } \\
\text { Interview }\end{array}$ & \\
\hline $1 *$ & 14 & 11 & $\mathrm{Y}$ & 31 & 4 & 2 & $\mathrm{~N}$ \\
\hline $2 *$ & 16 & 7 & $\mathrm{Y}$ & 32 & 2 & 3 & $\mathrm{~N}$ \\
\hline 3 & 0 & 1 & $\mathrm{Y}$ & 33 & 0 & 3 & $\mathrm{~N}$ \\
\hline 4 & 0 & 0 & $\mathrm{~N}$ & 34 & 4 & 3 & $\mathrm{~N}$ \\
\hline 5 & 4 & 10 & $\mathrm{Y}$ & 35 & 2 & 3 & $\mathrm{~N}$ \\
\hline $6 *$ & 8 & 5 & $\mathrm{Y}$ & 36 & 4 & 2 & $\mathrm{Y}$ \\
\hline $7 *$ & 12 & 7 & $\mathrm{Y}$ & 37 & 4 & 4 & $\mathrm{~N}$ \\
\hline 8 & 0 & 7 & $\mathrm{Y}$ & $38 *$ & 8 & 6 & $\mathrm{Y}$ \\
\hline 9 & 2 & 0 & $\mathrm{Y}$ & 39 & 0 & 1 & $\mathrm{~N}$ \\
\hline $10 *$ & 16 & 11 & $\mathrm{Y}$ & 40 & 2 & 5 & $\mathrm{~N}$ \\
\hline $11 *$ & 9 & 5 & $\mathrm{Y}$ & 41 & 6 & 0 & $\mathrm{~N}$ \\
\hline 12 & 12 & 3 & $\mathrm{Y}$ & 42 & 6 & 1 & $\mathrm{~N}$ \\
\hline 13 & 0 & 2 & $\mathrm{~N}$ & 43 & 2 & 2 & $\mathrm{~N}$ \\
\hline $14^{*}$ & 12 & 8 & $\mathrm{Y}$ & 44 & 0 & 0 & $\mathrm{~N}$ \\
\hline 15 & 0 & 5 & $\mathrm{Y}$ & 45 & 4 & 2 & $\mathrm{~N}$ \\
\hline 16 & 4 & 7 & $\mathrm{Y}$ & 46 & 2 & 0 & $\mathrm{~N}$ \\
\hline 17 & 0 & 1 & $\mathrm{~N}$ & 47 & 2 & 2 & $\mathrm{~N}$ \\
\hline 18 & 8 & 4 & $\mathrm{Y}$ & 48 * & 10 & 5 & $\mathrm{Y}$ \\
\hline 19 & 0 & 2 & $\mathrm{~N}$ & 49 & 0 & 1 & $\mathrm{~N}$ \\
\hline 20 & 4 & 5 & $\mathrm{Y}$ & 50 & 2 & 0 & $\mathrm{~N}$ \\
\hline 21 * & 12 & 11 & $\mathrm{Y}$ & 51 & 2 & 4 & $\mathrm{~N}$ \\
\hline 22 & 4 & 3 & $\mathrm{Y}$ & 52 & 6 & 1 & $\mathrm{~N}$ \\
\hline $23 *$ & 14 & 7 & $\mathrm{Y}$ & 53 & 4 & 3 & $\mathrm{Y}$ \\
\hline 24 & 6 & 0 & $\mathrm{~N}$ & 54 & 4 & 0 & $\mathrm{~N}$ \\
\hline 25 & 0 & 4 & $\mathrm{Y}$ & $55^{*}$ & 10 & 8 & $\mathrm{Y}$ \\
\hline $26^{*}$ & 9 & 6 & $\mathrm{Y}$ & 56 & 2 & 6 & $\mathrm{Y}$ \\
\hline 27 & 4 & 5 & $\mathrm{Y}$ & 57 & 2 & 3 & $\mathrm{~N}$ \\
\hline $28 *$ & 12 & 11 & $\mathrm{Y}$ & 58 & 2 & 6 & $\mathrm{~N}$ \\
\hline 29 & 4 & 3 & $\mathrm{Y}$ & $59 *$ & 8 & 6 & $\mathrm{Y}$ \\
\hline 30 & 8 & 4 & $\mathrm{Y}$ & 60 & 0 & 5 & $\mathrm{~N}$ \\
\hline
\end{tabular}

Hyperacusic children are marked with asterisk $\left(^{*}\right)$. 
Prevalence of hyperacusis was $36.7 \%(n=11)$ in the study group and $13.3 \%(n=4)$ in the control group. Difference was statistically significant $(t=2.13, p=0.03, d=0.55)$ (Figure 5).

\section{Prevalence of hyperacusis}

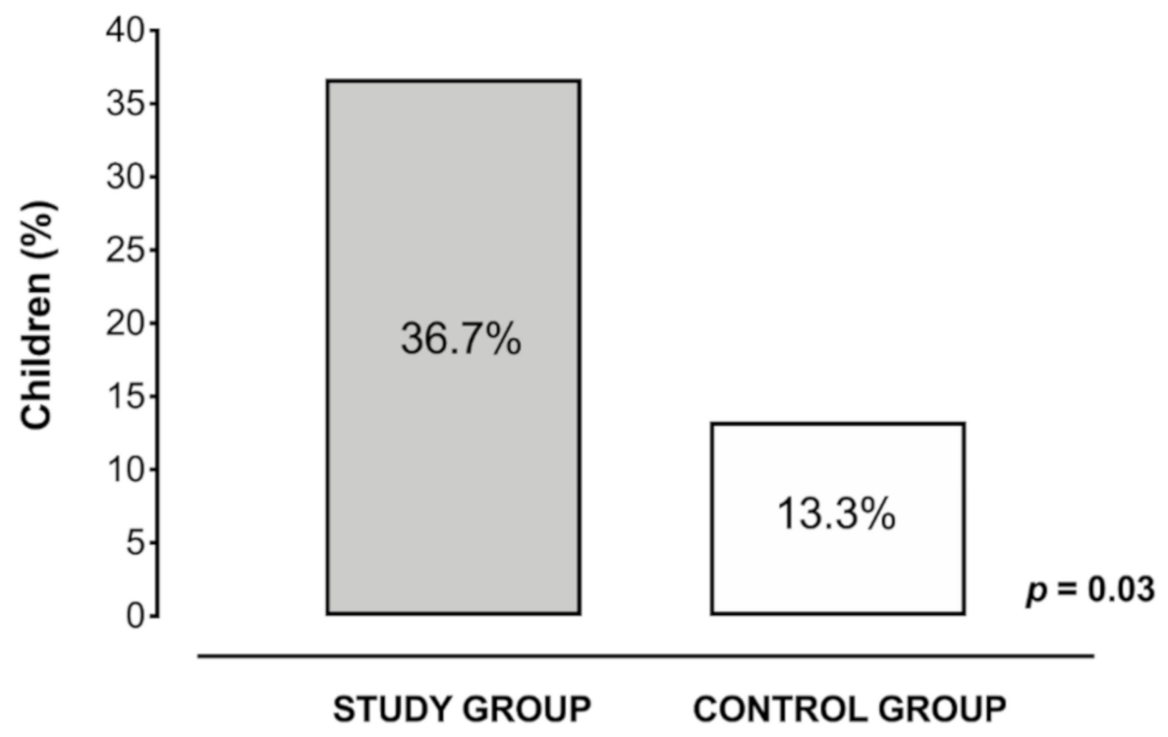

Figure 5. Prevalence of hyperacusis in children in the study group and control group calculated with positivity to both parent's questionnaire and children's interview. Prevalence of hyperacusis was $36.7 \%$ $(n=11)$ in the study group and $13.3 \%(n=4)$ in the control group. Difference was statistically significant $(p=0.03)$.

\section{Discussion}

The present study shows that the prevalence of hyperacusis in the study and control groups was, respectively, $36.7 \%$ and $13.3 \%$. These preliminary results, even if obtained from a small sample, suggest that hyperacusis may have a higher prevalence in children with a diagnosis of ADHD compared to otherwise healthy children. The majority of children included in the study were males; this is consistent with previous studies that reported an increased prevalence of hyperacusis in boys compared to girls $[12,16]$.

Comparing the prevalence of the control group with the data present in the literature, our prevalence $(13.3 \%)$ is within the range of 3.2-17.1\% identified in the Rosing review [31].

The higher prevalence of hyperacusis found in the study group suggests a potential association between ADHD and hyperacusis as already hypothesized by other authors [12,15,33], and is in line with the evidence that hyperacusis can be more frequent in children affected by neurodevelopmental disorders, in particular ASD [12,33,35,36,39-42]. Indeed, although different nosological entities, it is important to consider the relationship between ASD and ADHD: up to half of the children affected by ASD also present with ADHD (20-85\%) and 30-65\% of children with ADHD show autistic traits [43].

The most common responses to sounds in both groups were, in order of frequency: covering the ears for the duration of the sound, running away from the sound, and complaining of pain in the ears. In the study group, these reactions were more common compared to the control group. In our cohort of children, the most common annoying sounds included classroom noise, screams, school bells and bombs, in accordance with the sounds capable of causing hyperacusis observed in other studies [13,33]. Another observation is that the most annoying sounds were those that came from uncontrollable sound sources or were unpredictable. 
The mechanisms underlying hyperacusis in children are unknown in most cases and are even more difficult to identify in patients with neurodevelopment disorders [5,44-47]. In children affected by ASD, Khalfa hypothesized that hyperacusis can be the consequence of disordered loudness processing with a restricted dynamic range of perception, an increased subjective perception and reduced tolerance of loudness. This auditory hypersensitivity is found not only with loud sounds but also with sounds considered to be of moderate sound intensity [40]. Another important pathological mechanism causing hyperacusis and tinnitus in children with neurodevelopment disorders could be the sensory processing $[36,48,49]$. These patients may have difficulties in regulating or integrating sensory information (visual, touch, sounds, smells, proprioception), which can lead to patterns of hypersensitivity to sensory stimuli or a sensory overload effect [50-54]. This may be due to Sensory Over-Responsivity (SOR), a sensory modulation disorder manifested by behavioral responses that are faster, longer or more intense compared to peers [55]. SOR has been correlated in several studies with neurodevelopmental disorders such as ADHD and ASD [56-60]. Moller and Rollins [61] have hypothesized that in these children, hyperacusis may be the result of an alteration of non-classical auditory pathways with involvement of the limbic system. This could explain the intense emotional reactions in response to exposure to the troublesome sounds and could be related to an irritability condition that could have worsened children's reactions to sound.

Another important element is the relationship between hyperacusis and attention and cognitive functioning in children with ADHD. Children with a diagnosis of ADHD have difficulty in maintaining attention on specific tasks and inhibiting visual and sound distractors [62-64]. Such inability to inhibit an answer may explain many of the behavioral symptoms, including hyperactivity, impulsiveness, hyperacusis, and cognitive symptoms [62-64]. Fabio et al. analyzed the characteristics of auditory vigilance in ADHD subjects with and without interference, evaluating if deficits of the executive function are at least partly due to a deficit in automatic processing, and reported that children with ADHD exhibit a deficit both in automatic and controlled processes $[65,66]$.

The diagnosis of hyperacusis in a pediatric age is complex and not yet standardized, and consists of three phases: medical history, audiological evaluation and use of specific questionnaires [12,14,33]. Other proposed evaluation methods include the study of loudness discomfort levels and of the stapedial reflex [13,67]. In the authors' opinion, the investigation of possible hyperacusis in children should be mainly based on anamnestic history, observation and questionnaires aimed at collecting information about reactions to troublesome sounds and situations, use of safety behaviors, and impact of sound exposure on the activities of the child and the family. The lack of a universal agreement on the usefulness of the loudness discomfort levels and the use of the stapedial reflex to investigate hyperacusis led us to the choice not to use them in the audiological diagnostic phase, as they are more likely to lead to distress than give significant information [33].

Evidence on the treatment of hyperacusis in children is still fragmented. Amir et al., reported good therapeutic results with behavioral therapy, in which reassurance and explanation of the condition tailored to the child's individual characteristics was used to assist children in developing their own coping mechanisms and relaxation strategies; in most cases, this approach was also combined with sound therapy [12].

\section{Limits of Our Study}

Our study presents several limits. The main limit is the small size of our sample; larger studies are necessary to confirm our results. Secondly, the study design does not allow differentiation between hyperacusis, misophonia and phonophobia, leading to a possible confusion between these conditions. Similarly, SOR has not being investigated in the present study. Only children with a diagnosis of ADHD, combined presentation, were included to make the sample more homogeneous, while children with predominantly inattentive or predominantly hyperactive/impulsive ADHD presentations were excluded. Hyperacusis has been evaluated using a questionnaire; this tool has been modified and translated into Italian from the one validated by Coelho in 2007 [13]. No objective methods such as LDL 
and acoustic reflex studies have been used to assess hyperacusis because their use is still debated in children with hyperacusis. Lastly, the questionnaire has not been validated yet in the Italian language; future studies will contribute to validation.

\section{Conclusions}

The preliminary results of our study confirm a higher number of children with hyperacusis among those with ADHD compared to that of the general population of a similar age. The higher prevalence of hyperacusis in ADHD suggests that performing a neuropsychiatric assessment in all children complaining of hyperacusis who come to the attention of the otolaryngologist/audiologist would be useful. Similarly, it is advisable that all children with ADHD undergo an audiological evaluation to investigate the presence of hyperacusis. In fact, hyperacusis may worsen the typical symptoms of ADHD, resulting in a deterioration of the quality of life for children and their families and may contribute to the failure of cognitive-behavioral therapy. More studies on larger samples are necessary to confirm our preliminary data.

Author Contributions: M.R. (Massimo Ralli) contributed to the design and writing of the paper, F.Y.R., A.Z. and M.G.C. performed audiological evaluation, M.R. (Maria Romani) performed neuropsychiatric investigations, M.P.O. and G.A. performed the review of the literature, formal analysis and project administration, R.P. and R.T. critically reviewed the paper, supervised the work and provided experimental insights and contributed to its final edition. All authors have read and agreed to the published version of the manuscript.

Funding: The Authors have not received financial support for this research and work.

Acknowledgments: We thank the technicians who performed the audiological and neuropsychiatric tests and the parents of the enrolled children.

Conflicts of Interest: The authors declare no conflict of interest.

\section{References}

1. Aazh, H.; McFerran, D.; Salvi, R.; Prasher, D.; Jastreboff, M.; Jastreboff, P. Insights from the First International Conference on Hyperacusis: Causes, evaluation, diagnosis and treatment. Noise Health 2014, 16, 123-126. [CrossRef] [PubMed]

2. Chen, Y.C.; Li, X.; Liu, L.; Wang, J.; Lu, C.Q.; Yang, M.; Jiao, Y.; Zang, F.C.; Radziwon, K.; Chen, G.D.; et al. Tinnitus and hyperacusis involve hyperactivity and enhanced connectivity in auditory-limbic-arousal-cerebellar network. eLife 2015, 4, e06576. [CrossRef] [PubMed]

3. Middleton, J.W.; Tzounopoulos, T. Imaging the neural correlates of tinnitus: A comparison between animal models and human studies. Front. Syst. Neurosci. 2012, 6, 35. [CrossRef]

4. Auerbach, B.D.; Rodrigues, P.V.; Salvi, R.J. Central gain control in tinnitus and hyperacusis. Front. Neurol. 2014, 5, 206. [CrossRef] [PubMed]

5. Baguley, D.M. Hyperacusis. J. R. Soc. Med. 2003, 96, 582-585. [CrossRef] [PubMed]

6. Katzenell, U.; Segal, S. Hyperacusis: Review and clinical guidelines. Otol. Neurotol. 2001, 22, 321-327. [CrossRef]

7. Tyler, R.S.; Pienkowski, M.; Roncancio, E.R.; Jun, H.J.; Brozoski, T.; Dauman, N.; Dauman, N.; Andersson, G.; Keiner, A.J.; Cacace, A.T.; et al. A review of hyperacusis and future directions: Part I. Definitions and manifestations. Am. J. Audiol. 2014, 23, 402-419. [CrossRef]

8. Ralli, M.; Salvi, R.J.; Greco, A.; Turchetta, R.; De Virgilio, A.; Altissimi, G.; Attanasio, G.; Cianfrone, G.; de Vincentiis, M. Characteristics of somatic tinnitus patients with and without hyperacusis. PLoS ONE 2017, 12, e0188255. [CrossRef]

9. Hwang, J.H.; Chou, P.H.; Wu, C.W.; Chen, J.H.; Liu, T.C. Brain activation in patients with idiopathic hyperacusis. Am. J. Otolaryngol. 2009, 30, 432-434. [CrossRef]

10. Veuillet, E.; Khalfa, S.; Collet, L. Clinical relevance of medial efferent auditory pathways. Scand. Audiol. Suppl. 1999, 51, 53-62.

11. Ralli, M.; Greco, A.; Altissimi, G.; Tagliaferri, N.; Carchiolo, L.; Turchetta, R.; Fusconi, M.; Polimeni, A.; Cianfrone, G.; Vincentiis, M. Hyperacusis in Children: A Preliminary Study on the Effects of Hypersensitivity to Sound on Speech and Language. Int. Tinnitus J. 2018, 22, 10-18. [CrossRef] [PubMed] 
12. Amir, I.; Lamerton, D.; Montague, M.L. Hyperacusis in children: The Edinburgh experience. Int. J. Pediatr. Otorhinolaryngol. 2018, 112, 39-44. [CrossRef] [PubMed]

13. Coelho, C.B.; Sanchez, T.G.; Tyler, R.S. Hyperacusis, sound annoyance, and loudness hypersensitivity in children. Prog. Brain. Res. 2007, 166, 169-178.

14. Nemholt, S.S.; Schmidt, J.H.; Wedderkopp, N.; Baguley, D.M. Prevalence of tinnitus and/or hyperacusis in children and adolescents: Study protocol for a systematic review. BMJ Open 2015, 5, e006649. [CrossRef]

15. Paulin, J.; Andersson, L.; Nordin, S. Characteristics of hyperacusis in the general population. Noise Health 2016, 18, 178-184. [CrossRef]

16. Hall, A.J.; Humphriss, R.; Baguley, D.M.; Parker, M.; Steer, C.D. Prevalence and risk factors for reduced sound tolerance (hyperacusis) in children. Int. J. Audiol. 2016, 55, 135-141. [CrossRef]

17. Elsabbagh, M.; Cohen, H.; Cohen, M.; Rosen, S.; Karmiloff-Smith, A. Severity of hyperacusis predicts individual differences in speech perception in Williams Syndrome. J. Intellect. Disabil. Res. 2011, 55, 563-571. [CrossRef] [PubMed]

18. Carvalho Ade, J.; Lemos, S.M.; Goulart, L.M. Language development and its relation to social behavior and family and school environments: A systematic review. CoDAS 2016, 28, 470-479. [PubMed]

19. Barkley, R.A.; Brown, T.E. Unrecognized attention-deficit/hyperactivity disorder in adults presenting with other psychiatric disorders. CNS Spectr. 2008, 13, 977-984. [CrossRef] [PubMed]

20. Kessler, R.C.; Adler, L.; Barkley, R.; Biederman, J.; Conners, C.K.; Demler, O.; Faraone, S.V.; Greenhill, L.L.; Howes, M.J.; Secnik, K.; et al. The prevalence and correlates of adult ADHD in the United States: Results from the National Comorbidity Survey Replication. Am. J. Psychiatry 2006, 163, 716-723. [CrossRef]

21. Thomas, R.; Sanders, S.; Doust, J.; Beller, E.; Glasziou, P. Prevalence of attention-deficit/hyperactivity disorder: A systematic review and meta-analysis. J. Pediatrics 2015, 135, e994-e1001. [CrossRef] [PubMed]

22. Fayyad, J.; De Graaf, R.; Kessler, R.; Alonso, J.; Angermeyer, M.; Demyttenaere, K.; De Girolamo, G.; Haro, J.M.; Karam, E.G.; Lara, C.; et al. Cross-national prevalence and correlates of adult attention-deficit hyperactivity disorder. Br. J. Psychiatry 2007, 190, 402-409. [CrossRef]

23. Faraone, S.V.; Sergeant, J.; Gillberg, C.; Biederman, J. The worldwide prevalence of ADHD: Is it an American condition? World Psychiatry 2003, 2, 104-113. [PubMed]

24. Salmeron, P.A. Childhood and adolescent attention-deficit hyperactivity disorder: Diagnosis, clinical practice guidelines, and social implications. J. Am. Acad. Nurse Pract. 2009, 21, 488-497. [CrossRef] [PubMed]

25. Adler, L.A. Diagnosing and treating adult ADHD and comorbid conditions. J. Clin. Psychiatry 2008, 69, e31. [CrossRef]

26. Biederman, J.; Faraone, S.V.; Spencer, T.; Wilens, T.; Norman, D.; Lapey, K.A.; Mick, E.; Lehman, B.K.; Doyle, A. Patterns of psychiatric comorbidity, cognition, and psychosocial functioning in adults with attention deficit hyperactivity disorder. Am. J. Psychiatry 1993, 150, 1792-1798.

27. Fuermaier, A.B.M.; Hupen, P.; De Vries, S.M.; Muller, M.; Kok, F.M.; Koerts, J.; Heutink, J.; Tucha, L.; Gerlach, M.; Tucha, O. Perception in attention deficit hyperactivity disorder. Atten. Defic. Hyperact. Disord. 2018, 10, 21-47. [CrossRef]

28. Kaat, A.J.; Gadow, K.D.; Lecavalier, L. Psychiatric symptom impairment in children with autism spectrum disorders. J. Abnorm. Child. Psychol. 2013, 41, 959-969. [CrossRef]

29. Jensen, C.M.; Steinhausen, H.C. Comorbid mental disorders in children and adolescents with attention-deficit/hyperactivity disorder in a large nationwide study. Atten. Defic. Hyperact. Disord. 2015, 7, 27-38. [CrossRef]

30. Thapar, A. Discoveries on the Genetics of ADHD in the 21st Century: New Findings and Their Implications. Am. J. Psychiatry 2018, 175, 943-950. [CrossRef]

31. Rosing, S.N.; Schmidt, J.H.; Wedderkopp, N.; Baguley, D.M. Prevalence of tinnitus and hyperacusis in children and adolescents: A systematic review. BMJ Open 2016, 6, e010596. [CrossRef] [PubMed]

32. Johnson, L.B.; Comeau, M.; Clarke, K.D. Hyperacusis in Williams syndrome. J. Otolaryngol. 2001, 30, 90-92. [CrossRef] [PubMed]

33. Myne, S.; Kennedy, V. Hyperacusis in children: A clinical profile. Int. J. Pediatr. Otorhinolaryngol. 2018, 107, 80-85. [CrossRef] [PubMed]

34. Klein, A.J.; Armstrong, B.L.; Greer, M.K.; Brown, F.R., III. Hyperacusis and otitis media in individuals with Williams syndrome. J. Speech Hear. Disord. 1990, 55, 339-344. [CrossRef] [PubMed] 
35. Thabet, E.M.; Zaghloul, H.S. Auditory profile and high resolution CT scan in autism spectrum disorders children with auditory hypersensitivity. Eur. Arch. Otorhinolaryngol. 2013, 270, 2353-2358. [CrossRef]

36. Wilson, U.S.; Sadler, K.M.; Hancock, K.E.; Guinan, J.J., Jr.; Lichtenhan, J.T. Efferent inhibition strength is a physiological correlate of hyperacusis in children with autism spectrum disorder. J. Neurophysiol. 2017, 118, 1164-1172. [CrossRef] [PubMed]

37. American Academy of Otolaryngology and the American Council of Otolaryngology. Guide for the evaluation of hearing handicap. JAMA 1979, 241, 2055-2059. [CrossRef]

38. Posner, J.; Polanczyk, G.V.; Sonuga-Barke, E. Attention-deficit hyperactivity disorder. Lancet 2020, 395, 450-462. [CrossRef]

39. Ida-Eto, M.; Hara, N.; Ohkawara, T.; Narita, M. Mechanism of auditory hypersensitivity in human autism using autism model rats. Pediatr. Int. 2017, 59, 404-407. [CrossRef]

40. Khalfa, S.; Bruneau, N.; Roge, B.; Georgieff, N.; Veuillet, E.; Adrien, J.L.; Barthelemy, C.; Collet, L. Increased perception of loudness in autism. Hear. Res. 2004, 198, 87-92. [CrossRef]

41. Aazh, H.; Knipper, M.; Danesh, A.A.; Cavanna, A.E.; Andersson, L.; Paulin, J.; Schecklmann, M.; Heinonen-Guzejev, M.; Moore, B.C.J. Insights from the third international conference on hyperacusis: Causes, evaluation, diagnosis, and treatment. Noise Health 2018, 20, 162-170. [PubMed]

42. Danesh, A.A.; Lang, D.; Kaf, W.; Andreassen, W.D.; Scott, J.; Eshraghi, A.A. Tinnitus and hyperacusis in autism spectrum disorders with emphasis on high functioning individuals diagnosed with Asperger's Syndrome. Int. J. Pediatr. Otorhinolaryngol. 2015, 79, 1683-1688. [CrossRef] [PubMed]

43. Matson, J.L.; Rieske, R.D.; Williams, L.W. The relationship between autism spectrum disorders and attention-deficit/hyperactivity disorder: An overview. Res. Dev. Disabil. 2013, 34, 2475-2484. [CrossRef] [PubMed]

44. Roberts, L.E.; Salvi, R. Overview: Hearing loss, tinnitus, hyperacusis, and the role of central gain. Neuroscience 2019, 407, 1-7. [CrossRef] [PubMed]

45. Aazh, H.; McFerran, D.; Moore, B.C.J. Uncomfortable loudness levels among children and adolescents seeking help for tinnitus and/or hyperacusis. Int. J. Audiol. 2018, 57, 618-623. [CrossRef]

46. Moller, A.R.; Salvi, R.; De Ridder, D.; Kleinjung, T.; Vanneste, S. Pathology of Tinnitus and Hyperacusis-Clinical Implications. Biomed. Res. Int. 2015, 2015, 608437. [CrossRef]

47. Jastreboff, P.J.; Jastreboff, M.M. Decreased sound tolerance: Hyperacusis, misophonia, diplacousis, and polyacousis. Handb. Clin. Neurol. 2015, 129, 375-387.

48. Sedley, W. Tinnitus: Does Gain Explain? Neuroscience 2019, 407, 213-228. [CrossRef]

49. Brotherton, H.; Plack, C.J.; Maslin, M.; Schaette, R.; Munro, K.J. Pump up the volume: Could excessive neural gain explain tinnitus and hyperacusis? Audiol. Neurootol. 2015, 20, 273-282. [CrossRef]

50. Chemali, Z.; Nehme, R.; Fricchione, G. Sensory neurologic disorders: Tinnitus. Handb. Clin. Neurol. 2019, 165, 365-381.

51. Jones, E.J.H.; Dawson, G.; Webb, S.J. Sensory hypersensitivity predicts enhanced attention capture by faces in the early development of ASD. Dev. Cogn. Neurosci. 2018, 29, 11-20. [CrossRef] [PubMed]

52. Takarae, Y.; Sablich, S.R.; White, S.P.; Sweeney, J.A. Neurophysiological hyperresponsivity to sensory input in autism spectrum disorders. J. Neurodev. Disord. 2016, 8, 29. [CrossRef] [PubMed]

53. Panagopoulos, V.N.; Greene, D.J.; Campbell, M.C.; Black, K.J. Towards objectively quantifying sensory hypersensitivity: A pilot study of the "Ariana effect". Peer] 2013, 1, e121. [CrossRef] [PubMed]

54. Ghanizadeh, A. Tactile sensory dysfunction in children with ADHD. Behav. Neurol. 2008, 20, 107-112. [CrossRef] [PubMed]

55. Miller, L.J.; Anzalone, M.E.; Lane, S.J.; Cermak, S.A.; Osten, E.T. Concept evolution in sensory integration: A proposed nosology for diagnosis. Am. J. Occup. Ther. 2007, 61, 135-140. [CrossRef] [PubMed]

56. Tomchek, S.D.; Dunn, W. Sensory processing in children with and without autism: A comparative study using the short sensory profile. Am. J. Occup. Ther. 2007, 61, 190-200. [CrossRef] [PubMed]

57. Yochman, A.; Ornoy, A.; Parush, S. Co-occurrence of developmental delays among preschool children with attention-deficit-hyperactivity disorder. Dev. Med. Child. Neurol. 2006, 48, 483-488. [CrossRef]

58. Rogers, S.J.; Hepburn, S.; Wehner, E. Parent reports of sensory symptoms in toddlers with autism and those with other developmental disorders. J. Autism Dev. Disord. 2003, 33, 631-642. [CrossRef]

59. Dunn, W.; Myles, B.S.; Orr, S. Sensory processing issues associated with Asperger syndrome: A preliminary investigation. Am. J. Occup. Ther. 2002, 56, 97-102. [CrossRef] 
60. Mangeot, S.D.; Miller, L.J.; McIntosh, D.N.; McGrath-Clarke, J.; Simon, J.; Hagerman, R.J.; Goldson, E. Sensory modulation dysfunction in children with attention-deficit-hyperactivity disorder. Dev. Med. Child. Neurol. 2001, 43, 399-406. [CrossRef]

61. Moller, A.R.; Rollins, P.R. The non-classical auditory pathways are involved in hearing in children but not in adults. Neurosci. Lett. 2002, 319, 41-44. [CrossRef]

62. Gibson, B.S.; Healey, M.K.; Gondoli, D.M. ADHD reflects impaired externally directed and enhanced internally directed attention in the immediate free-recall task. J. Abnorm. Psychol. 2019, 128, 173-183. [CrossRef] [PubMed]

63. Lin, H.Y.; Hsieh, H.C.; Lee, P.; Hong, F.Y.; Chang, W.D.; Liu, K.C. Auditory and Visual Attention Performance in Children With ADHD: The Attentional Deficiency of ADHD Is Modality Specific. J. Atten. Disord. 2017, 21, 856-864. [CrossRef]

64. McAvinue, L.P.; Vangkilde, S.; Johnson, K.A.; Habekost, T.; Kyllingsbaek, S.; Bundesen, C.; Robertson, I.H. A Componential Analysis of Visual Attention in Children With ADHD. J. Atten. Disord. 2015, 19, 882-894. [CrossRef] [PubMed]

65. Capri, T.; Santoddi, E.; Fabio, R.A. Multi-Source Interference Task paradigm to enhance automatic and controlled processes in ADHD. Res. Dev. Disabil. 2020, 97, 103542. [CrossRef] [PubMed]

66. Fabio, R.A.; Castriciano, C.; Rondanini, A. ADHD: Auditory and Visual Stimuli in Automatic and Controlled Processes. J. Atten. Disord. 2015, 19, 771-778. [CrossRef] [PubMed]

67. Sheldrake, J.; Diehl, P.U.; Schaette, R. Audiometric characteristics of hyperacusis patients. Front. Neurol. 2015, 6, 105. [CrossRef] [PubMed]

(C) 2020 by the authors. Licensee MDPI, Basel, Switzerland. This article is an open access article distributed under the terms and conditions of the Creative Commons Attribution (CC BY) license (http://creativecommons.org/licenses/by/4.0/). 